\title{
Exploring The Influence of COVID-19 on Initial Teacher Education in Malta: Student Participation in Higher Education
}

Charmaine Bonello, Josephine Deguara, Rosienne Farrugia, Suzanne Gatt, Tania Muscat, Josephine Milton, Lara Said, Jane Spiteri

Department of Early Childhood and Primary Education, Faculty of Education, University of Malta, Malta.

\begin{abstract}
The COVID-19 pandemic forced a rapid transition from onsite to online learning spaces for initial teacher education (ITE); with Universities adopting new modes of pedagogy and assessment. This study explores: (1) how Maltese ITE undergraduate early years and postgraduate primary education students dealt with remote forms of learning during the early stages of the pandemic in Malta, and (2) the teaching/lecturing modes used, by lecturers, for remote learning, assessment and the impact on student wellbeing. The data were gathered through an online quantitative survey designed to collect information about ITE students' views. Students' responses obtained strongly suggest that in the eventuality of an ongoing 'postvaccination COVID' era, ITE within HE programmes should consider revisiting the course content and delivery, supporting and fostering, blended and online approaches. A 'blind spot' reflecting the struggle for independence, autonomy, and control during COVID-19 in a postcolonial Maltese Higher Education context also emerged. The insights gained highlight how ITE students' views on their experiences of predominantly online pedagogy and assessment, and how the impact on their wellbeing within a Maltese HE context can serve to promote the development of ITE programmes. These results also emphasize the need to promote participatory research amongst university students as key to inform HE policy and practice.
\end{abstract}

Keywords: Initial teacher education; online learning; COVID-19; student participation; Higher Education. 


\section{Introduction}

The SARS-CoV-2 (COVID-19) has led to a global health crisis that has impacted the quality of education and the mode of delivery, process and outcome of learning at all levels of education (United Nations, 2020). Many countries were forced to close educational facilities such as Universities. This closure has considerably disrupted the quality of teaching/lecturing within Universities and altered students' learning trajectories. COVID-19 has also created opportunities for teacher education (United Nations, 2020) with an increase in students enrolling in teacher training programs (Worth \& McLean, 2020). It has also heralded the implementation of a digital transformation in teaching/learning in $\mathrm{HE}$ institutions; which usually take years to implement (Adedoyin \& Soykan, 2020). A critical challenge relates to how students interact with digital teaching and learning, in that littl is as yet known about the impact of online teaching and learning in ITE (Carrillo \& Flores, 2020). In Malta, during the first six months of the COVID-19 pandemic, the University of Malta, experienced a rapid transition from onsite face-to-face to remote teaching and learning, affecting education, including ITE (Carrillo \& Flores, 2020). This paper gives a voice to the students at the University of Malta and explores the influence of COVID-19 on their undergraduate/postgraduate ITE experiences through student participation.first section starts on page two. Paper length must be between 4 and 8 pages (A4 size), incorporating all text, references, figures and tables. These guidelines are strict: papers failing to adhere to the guidelines (by being more than 8 pages, altering margins or not following the template) will be rejected without consideration of their merits.

\section{Literature review: The impact of COVID-19 on HE and ITE}

An important consequence of COVID-19 for HE was the shift from face-to-face instruction to synchronous/asynchronous online modes of teaching and learning. Many universities, including the University of Malta (UM), already possessed a virtual learning environment (VLE). This sudden shift to online modes created challenges/hardships to academic staff/students (Allen, Rowan \& Singh, 2020) and had major academic, financial, social and physical implications for students (Donsita-Schmidt \& Ramot, 2020). Universities adopted new modes of assessment such as writing blogs, portfolios, production of interactive digital posters, podcasts, presentations, etc. Many assessments and exams were also held online (Donsita-Schmidt \& Ramot, 2020). ITE also experienced added challenges related to their trainee teachers' practical work experience in schools (Donsita- Schmidt \& Ramot, 2020). As school closure reduced the placements available, this also resulted in lost opportunities for teaching practice. Student teachers could find more time to read and to reflect in-depth, achieving improved overall grades (La Velle et al., 2020). Universities adopted different strategies to overcome ITE challenges such as having online work placements. However, online modes of teaching and learning are not always motivational to university students; 
and Maltese student teachers may not be any different. Isolation also impacted students' psychological wellbeing (Arnhold, et al., 2020). The intensity of interaction prevalent in teacher training programmes such as collaboration and cooperation, led some students to experience stress/burnout and exhibit this through an apparent lack of enthusiasm to participate actively in online learning.

\section{Aims and Objectives of the study}

The study explored how Maltese ITE for early years and primary education dealt with remote online learning during the pandemic, and how the pedagogies experienced impacted students' learning and wellbeing. The study included two groups of students from the Faculty of Education (FoE) at the University of Malta: those following a 3-year Bachelor degree in Early Childhood Education and Care (BA) (training to work with 3- to 5-year-old children); and Master in Teaching and Learning (MTL) students training to become primary teachers (working with 5- to 11-year- old children). The aim of this research was to understand the impact of COVID-19 on ITE students' overall learning and wellbeing through a student participatory research approach. The specific objectives were to explore: trainee educators' perceptions and experiences of online delivery modes in ITE; the impact of the shift to online learning on relationships and wellbeing; and ITE students' preferences of online pedagogies. The main research question set was: 'What lessons were learnt from the rapid shift to online modes of delivery in ITE during the first wave of COVID-19 pandemic?'. This was extended to the following subquestions: 'What were ITE students' perceptions and experiences of online teaching and learning and quality of learning, and how did it impinge on their relationships and overall wellbeing?', and 'What online pedagogies and strategies did the ITE students prefer?'

\section{Methodology}

The research methodology involved an anonymous online quantitative survey among University of Malta ITE students' about their experiences and views of their educational and personal lives during COVID-19. The survey was divided in four-sections and included 29 items, mainly multiple-choice and 5-point Likert scales. The featured sections included items about: participants' demographics; teaching/learning during the pandemic; learning spaces; and relationships and wellbeing. Following ethical clearance obtained from the Faculty of Education Research Ethics committee at the University, the necessary permissions were obtained to disseminate the survey through the University channels. Responses were collected between July and September 2020. A total of 127 ITE students (BA group $n=68$, MTL group $n=40$, not stated $n=19$ ) from a whole student population of 206 participated in the study. The majority of respondents were female at $94.5 \%(n=120)$ while $5.5 \%(n=7)$ were 
males. Students' ages ranged between 18 to 47 years. MTL students were on average aged 20.57 years old $(\mathrm{s} . \mathrm{d}=3.788)$, whilst BA students 19.01 years $(\mathrm{s} . \mathrm{d}=5.44)$. This older age for MTL students reflects the years needed prior to progression postgraduate professional Masters training in the case of primary school teachers.

\section{Results}

The students' responses reflect the use of a range of methods of online learning. The most popular were live online lectures, experienced very often by $52.4 \%$ of the students, and often by another $20.6 \%$. Many students also had documents uploaded on the University's Virtual Learning Environment (VLE) ('very often' for 50.0\% and 'often' for 29.6\%). Recorded online lectures were also used, but to a lesser degree, as were group tutorials on Zoom/Teams. Forums (synchronous or asynchronous) were also not frequent, with $30.0 \%$ only using them 'sometimes'. There was also limited interaction during live online sessions, with one third (20.8\% 'very often' and $12.5 \%$ 'often') using the mute button. Lectures were also teacher centred, as many (46.4\% 'very often' and 34.2\% 'often) declared that they took notes during the lectures. About half of the students $(45.92 \%)$ used the chat. It is also worth noting that the great majority never changed their name on screen, or left the lecture to do something else. Students were asked to express the impact of the different online modes on their learning. As figure 1. below shows, over half of the students enjoyed spontaneous sessions as they found it easy to participate actively and ask questions. They also felt more 'normal' in the COVID circumstances, as well as felt that the lecturer could plan better. Contrary to live online lectures, many students $(45.0 \%)$ did not feel that they learnt more with recorded lectures while for $27.9 \%$ it made no difference. Only over half (57.3\%) listened to a recorded lecture before the next one was uploaded. About one fifth of the students also often discussed the lectures with their classmates, while another $47.5 \%$ did this sometimes. Only $13.5 \%$ sometimes listened to lectures together with their classmates. However, the majority of the students liked listening to recorded lectures according to their schedule $(89.2 \%)$ and that they could stop the presentation to research material related to the lecture as they needed $(80.9 \%)$. They $(63.1 \%)$ also felt that it allowed them to discuss with classmates when they did not understand well. In comparing their learning experiences during COVID to normal university life, over $60 \%$ agreed that they spent more time following online lectures and doing task assignments. Their lectures did not decrease which shows that learning kept on going at a good pace. Their responses reflect divergent views with respect to whether it was easier to understand their lecturer when learning online, with about one quarter (26.3\%) not liking it, about one third (29.1\%) to whom it made no difference, and around $41 \%$ who found it easier. However, around half of the students found learning more difficult. $46 \%$ of students stated that they spent more time reading, and $41.67 \%$ said that they had more time to consolidate their learning. 




Figure 1. Impact on online learning.

There was an overall divergent opinion with respect to the quality of learning, with similar percentages stating that quality was higher, the same quality, and poorer (Figure 2). However, over half $(60.0 \%)$ of the students stated that they missed the face-to-face interaction and around $40.0 \%$ were concerned about lack of support for learners. About one third were more worried about reduced teaching time and content. One major concern for many $(66.20 \%)$ with respect to their wellbeing was that they could not maintain long hours of online engagement and that learning had become more teacher-centred (around 79\%). They also did not like that there was a diminished level of student engagement $(60.0 \%)$.

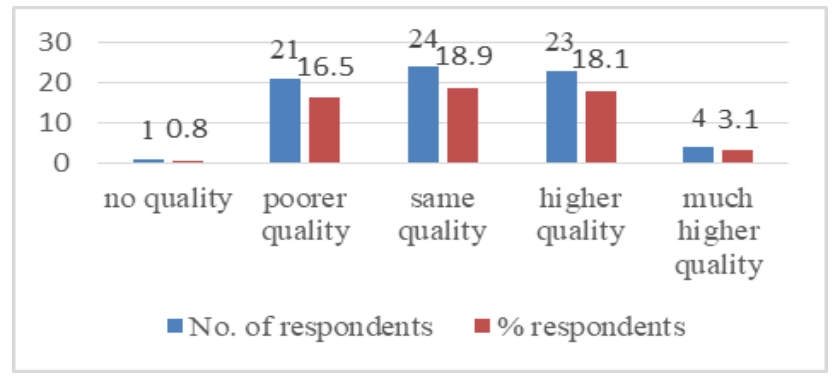

Figure 2. ITE's students' views on quality of learning during COVID.

These responses show that not only learning may have been harder for some during lockdown, but that even their wellbeing was impacted. On a positive note, quite a number of students seem to be resilient. In fact, many of the students indicated that the support of their family helped them deal with the COVID situation. As a Mediterranean country and culture, family structures are very important in Malta. This aspect has helped many of the students' wellbeing as they could deal better with the constraint of having to be physically separate from their friends. Students were also asked to indicate what they would keep from their learning experiences at post-COVID. It appears that, having experienced both online and 
face-to-face learning at University, that over half appreciated the positive aspects of both approaches, and were also positive with respect to keeping a blended approach (Figure 3 ). This has implications to ITE at post-COVID phase.

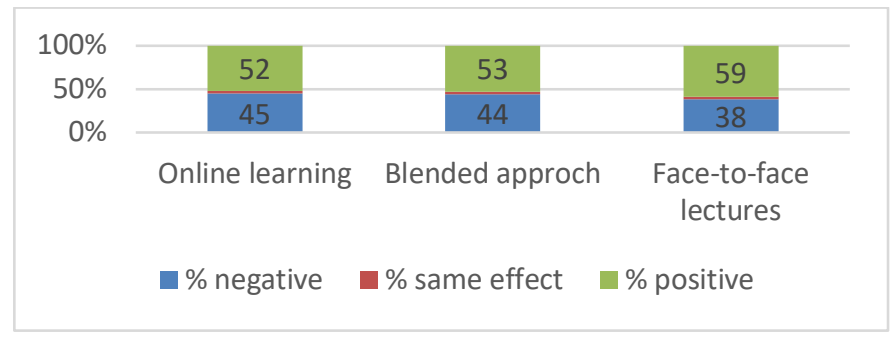

Figure 3. ITE students' preferences for different modes of learning.

\section{Discussion}

A conceptual model emerged from the impact of COVID-19 on ITE students. The model highlights tension in ITE students' psychological need and wellbeing; colonised legacies in HE; and a way forward for more inclusive learning for all. This first exploration study points strongly towards the need to conceptualize HE teaching and learning in ITE.

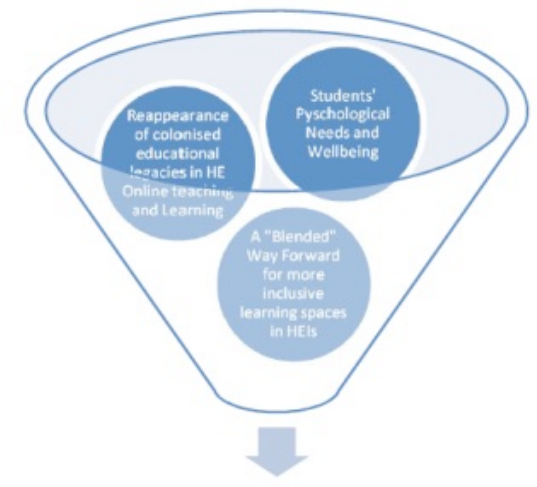

Reconceptualising Higher Education through Student Participation in Post-COVID times

Figure 4. Conceptual model on reconceptualising ITE within HE.

Theme 1: Battling a Crisis Online - Students'Psychological Needs and Wellbeing: Students' responses highlighted how they battled with COVID-19 limitations. Their positive views of spontaneous interaction with other students and lecturers reflected a craving need to belong and connect (relatedness). The students' voices highlighted how they (60\%) missed onsite 
face-to-face lecturing and (66\%) could not endure long hours of online engagement. These responses highlighted how the psychological need for wellbeing (Self Determination Theory) was not met for the majority of students who experienced stressful situations (Agormedah et al., 2020). This implies that if online lecturing is to be kept as part of students' teaching and learning modes in post-COVID, the number of daily online lectures need to be taken into consideration. The length of each online lecture could also be rethought together with the monitoring of quality eLearning is to be carried out.

Theme 2: A blind spot? Lingering colonised educational legacies in HE online teaching and learning in Malta: Using the Self Determination Theoretical lens (Deci \& Ryan, 1985), competence and autonomy in the new adopted modes of online learning appear to have decreased. Most students $(\mathrm{n}=79 \%)$, declared that learning was more teacher-centred, involving passive note taking and using the mute all button (transmission of knowledge). Students need to feel in control of learning (autonomy) to develop mastery of knowledge and skills (competence). Students have differing needs depending on their cultural and environment contexts. Not everyone will seek autonomy if others control the situation and here is where the culture structure of Malta becomes important. Malta, as an ex-British colony, has inherited a legacy of formal education, elements of which are still reflected within its 21 st century educational system (Baldacchino, 2019). Albeit the political, curricular and pedagogical efforts by local education professionals for a more progressive education philosophy, an existing 'blind spot', reflecting a dogged struggle for independence, autonomy, and control during COVID-19 in a postcolonial Maltese HE context has emerged. It is thus important for lecturers to engage in professional development on effective online teaching and learning to maximise and make remote eLearning more meaningful and responsive to today's students' needs.

Theme 3: The Way Forward - A Blended Approach for more inclusive learning spaces in a Post-COVID University of Malta? Individual differences in learning styles and preferences are rooted in childhoods and cultures and are reflected in the students' views on (i) the quality of remote online teaching and learning, and (ii) the preferences for future HE pedagogies. The University of Malta should take into account the students' voices by adopting a postCOVID blended and more inclusive teaching and learning approach through the integration of online and onsite face-to-face learning spaces. Also, in a post-COVID era, ITE within HE programmes should consider revisiting the course content and delivery through students' views to equip future teachers with the necessary values, knowledge and skills needed within their contexts.

\section{Conclusion}

This paper sought a deeper understanding of the impact of the COVID-19 pandemic on ITE students at the University of Malta. It highlighted the need to consider both students' learning as well as their wellbeing in ITE. Based on the findings, some recommendations for HEIs 
include: lead by 'listening' rather than 'talking' within a shared democratic vision; embrace students' right to active participation in HE; extend wellbeing services and assistance through outreach programmes; provide spaces in ITE programmes to deconstruct the roots of education philosophy before moving forward (reconstruct); promote learning that recognises students' individual needs, and increase their wellbeing; build and sustain an infrastructure for integrating blended learning; and implement quality and more inclusive learning spaces. The study has its limitations tied to a focus on ITE students in one HE institution in Malta. However, from a geopolitical angle, the sharing of students' teaching and learning experiences within HEIs in Europe, may serve as a valuable input for forthcoming discussions regarding higher education policy and reforms among European governments, policymakers and educators. Ultimately, it is the core mission of the Bologna process to enhance the quality of learning and teaching in HEIs, and student participatory research is key to inform policy and practice.

\section{References}

Adedoyin O., B. \& Soykan, E. (2020): COVID-19 pandemic and online learning: the challenges and opportunities, Interactive Learning Environments, DOI:10.1080/10494820.2020.1813180

Agormedah, E. K., Henaku, E. A., Ayite, D. M. K., \& Ansah, E. A. (2020). Online learning in Higher Education during COVID-19 pandemic: A case of Ghana. Journal of Educational Technology \& Online Learning, 3(3), 183-210.

Allen, J., Rowan, L., \& Singh, P. (2020). Teaching and teacher education in the time of COVID-19, Asia-Pacific Journal of Teacher Education, 48(3), 233-236. https://doi.org/10.1080/1359866X.2020.1752051.

Arnhold, N., Brajkovic, L., Nikolaev, D., \& Zvalina, P. (2020). Tertiary Education and Covid-19: Impact and Mitigation Strategies in Europe and Central Asia. Retrieved from: https://documents1.worldbank.org/curated/en/783451590702592897/COVID-19Impact-on-Tertiary-Education-in-Europe-and-Central-Asia.pdf.

Baldacchino, A. (2019). Postcolonialism and Early Childhood Education in Small Island States. Malta Review of Educational Research, 13(1), 109-130.

Carrillo, C., \& Flores, M. A. (2020). COVID-19 and teacher education: a literature review of online teaching and learning practices. European Journal of Teacher Education, 43(4), 466-487. https://doi.org/10.1080/02619768.2020.1821184.

Deci, E. L., \& Ryan, R. M. (1985). Intrinsic motivation and self-determination in human behavior. New York: Plenum.

La Velle, L., Newman, S., Montgomery, C., \& Hyatt, D. (2020). Initial teacher education in England and the Covid-19 pandemic: Challenges and opportunities. Journal of Education for Teaching, 46(4), 596-601. https://doi.org/10.1080/02607476.2020.1803051.

United Nations. (2020). Policy brief: Education during COVID-19 and beyond. Geneva: United Nations. Retrieved from: https:/www.un.org/development/desa/dspd/wp- 
content/uploads/sites/22/2020/08/sg_policy_brief_covid19_and_education_august_2020.pdf 